\title{
Blackleg Sporacle: A Model for Predicting Onset of Pseudothecia Maturity and Seasonal Ascospore Showers in Relation to Blackleg of Canola
}

\author{
M. U. Salam, R. K. Khangura, A. J. Diggle, and M. J. Barbetti
}

First author: Centre for Cropping Systems, Department of Agriculture-Western Australia, Lot 12 (P.O. Box 483), Northam, WA 6401, Australia; second, third, and fourth authors: Department of Agriculture-Western Australia, 3 Baron-Hay Court, South Perth, WA 6151, Australia; and third and fourth authors: Co-operative Research Centre for Legumes in Mediterranean Agriculture and Soil Science Discipline, School of Earth and Geographical Sciences, Natural and Agricultural Sciences, respectively, University of Western Australia, Crawley, WA 6009, Australia.

Accepted for publication 22 March 2003.

\section{ABSTRACT}

Salam, M. U., Khangura, R. K., Diggle, A. J., and Barbetti, M. J. 2003. Blackleg Sporacle: A model for predicting onset of pseudothecia maturity and seasonal ascospore showers in relation to blackleg of canola. Phytopathology 93:1073-1081.

A simple model has been developed to predict the onset of pseudothecia maturity and seasonal ascospore showers in relation to blackleg disease in canola, caused by the fungus Leptosphaeria maculans. The model considers a combination of two weather factors, daily mean temperature and daily total rainfall, to drive progress of maturity of pseudothecia on the infested canola stubble left from past crops. Each day is categorized as suitable or not suitable for progress of the maturation process. The onset of pseudothecia maturity occurs when approximately 43 suitable days have occurred. Following the onset of maturity, ascospore showers are triggered when daily rainfall exceeds a threshold. The model satisfactorily predicted the timing of the onset of pseudothecia maturity when tested with 3 years of field observations at four locations in Western Australia, which characteristically has a Mediterranean climate. The model also agreed reasonably well with the daily pattern of ascospore release observed in two locations. Sensitivity analysis was performed to show the relative importance of the parameters that describe the onset of pseudothecia maturity.

Additional keywords: ascospore discharge, oilseed rape, Phoma lingam, stem canker.
Blackleg (phoma stem canker, stem canker), caused by Leptosphaeria maculans (Desm.) Ces. \& de Not. (anamorph Phoma lingam (Tode:Fr.) Desm.), is a common disease of canola (Brassica napus L.) and oilseed rape (rape seed, B. rapa L.). West et al. (25) has highlighted the economic importance of this disease in major canola growing regions of the world, especially in Australia, Canada, and Europe. The disease is also a concern in the United States (5). At their worst, blackleg epidemics may be so severe as to disrupt the entire canola growing industry in whole regions as occurred in Australia in the early 1970s (2). Improved cultivar resistance, in recent years, has had a positive impact on canola production by minimizing yield loss from blackleg, especially in Australia. However, most of the current cultivars have only adult plant resistance (20), leaving the seedlings prone to infection during their early growth stages. In fact, the major yieldreducing infections are the ones that occur at an early stage in the life of the plant. Thus, blackleg management is still an integral part of canola production in Australia and in many other canola growing regions of the world, including Canada and Europe.

Blackleg epidemics in canola are primarily initiated by airborne ascospores of $L$. maculans $(2,5,10,24,25)$. After harvest of the crop, the fungus survives as a saprophyte (27) on infected stubble. Pseudothecia (ascocarps) of the fungus form readily on the woody remains of the infected plants (10), and the timing of pseudothecia maturity and subsequent ascospore release appears to be related to weather conditions after harvest (8). Once pseudothecia are matured, rainfall (4) and/or heavy dews and high humidity (10)

Corresponding author: M. U. Salam; E-mail address: msalam@agric.wa.gov.au

Publication no. P-2003-0701-01R

(c) 2003 The American Phytopathological Society trigger ascospore release. Wind blows the aerosol ascospores to distances as great as $5 \mathrm{~km}$ from the infested stubble (4). After maturity, pseudothecia on the stubble release a succession of ascospore showers. Depending on environment, the release of ascospores continues for a period of 3 to 4 months or longer with a peak usually occurring 1 or 2 months after its onset $(7,10,22)$.

Investigations in controlled environment and in the field have been carried out in a wide range of conditions to measure ascospore concentration and its seasonal discharge pattern $(5,7,8,10$, $11,14,17,19,22)$. This information is crucial both for understanding the epidemiology of blackleg and for formulating strategies for disease management. Results indicate that the temporal pattern of ascospore discharge varies between locations within a season $(8,19,22)$ and between seasons within a location $(8,17,22)$. The predominant cause of variation in the initiation of ascospore release is difference in the timing of pseudothecia maturity $(7,22$, 24). This variability makes it difficult to formulate both strategic and tactical decisions on blackleg management at regional and farm scales (24). This difficulty would be overcome if a reliable system for forecasting ascospore release could be developed.

Two approaches could be adopted to develop such a forecasting system. Firstly, pseudothecia maturity could be observed directly on stubble samples and canola growers could be warned when ascospore release is imminent. Secondly, pseudothecia maturity and timing of ascospore showers could be forecast using simulation based on weather conditions. The former approach can potentially provide accurate information but has several disadvantages. Such measurements are time-consuming and require considerable expertise to perform. Consequently, they are expensive and typically have a long turn around time. Those problems could be overcome by adopting the latter approach, i.e., the weather-based forecasting system. However, the challenge would be to develop an accurate and robust system that is simple to operate. 
Attempts have been made to explain the variability in the pattern of ascospore showers over 13 seasons in Saskatchewan, Canada, by relating ascospore numbers to preseasonal temperature, rainfall, and other weather factors (17). However, simple relationships (such as correlation) did not fully explain seasonal variability in ascospore discharge pattern. A number of investigations have been carried out in France $(13,14,18)$ and a few in England (26) to relate weather factors to the maturity of pseudothecia $(13,14,18)$. It appears that preseasonal temperature and wetness are the main weather factors that influence maturation of pseudothecia $(3,12,24)$. It has been reported that the first release of ascospores in France occurs 16 to 19 rain-days after harvest, when the average temperature reaches around $14^{\circ} \mathrm{C}$ (12). With these assumptions, the French researchers forecast pseudothecia maturity in their environments (1). To date, to our knowledge, a simulation model capable of predicting pseudothecia maturity (and/or first ascospore release) based on weather conditions has not been developed.

Considering the above, we have developed a simple model to predict the onset of pseudothecia maturity of blackleg fungus, $L$. maculans, in relation to temperature and rainfall in the preseasonal summer and/or autumn period. The model also predicts the dynamics of ascospore showers based on proportion of mature pseudothecia, with release triggered by rainfall. The aims of this paper are to (i) describe the model, (ii) test the model under diverse agricultural regions of Western Australia, and (iii) perform sensitivity analysis of the parameters that dictate onset of pseudothecia maturity.

\section{MATERIALS AND METHODS}

Description of the model. Blackleg Sporacle has two parts, (i) prediction of onset of pseudothecia maturity, and (ii) prediction of seasonal ascospore showers. The pseudothecia maturation process has been observed to progress when cool temperature occurs in combination with wet conditions. This basic hypothesis, based on a review of relevant literature $(3,12,24)$ and on local experience, has been applied to formulate the model to describe and quantify the onset of pseudothecia maturity. After pseudothecia maturity, mature ascospores are discharged from pseudothecia when a threshold level of wetness is exceeded $(4,10)$. From this additional assumption, the seasonal ascospore shower prediction model has been constructed.

Predicting onset of pseudothecia maturity. Each day following harvest of canola is classified as either favorable for pseudothecia maturity (FPM) or not. A day is FPM if the mean daily temperature for the preceding 10-day period is less than a threshold value ( $T$ _threshold), and the total rainfall for the last 7 days is greater than or equal to a threshold ( $R \_$threshold). A running total of FPM days is maintained. The date when a specified total of FPM days is reached is used as an estimator of the date of onset of pseudothecia maturity (PM_begin). The relationship between temporal patterns of temperature and wetness and the process of maturation of pseudothecia is incompletely understood but probably complex. Because comprehensive and detailed experimental results are not available, threshold functions have been chosen to represent the relationship. These threshold functions have a minimum number of parameters but they can reproduce the major observed trends. It is expected that inaccuracies in these threshold functions will be compensated for to some extent in the process of fitting to field data. T_threshold, $R \_$threshold, the durations of the time periods used in calculating these values, T_threshold_duration and $R \_$threshold_duration, and $P M \_$begin are parameters of the model and are discussed in the model parameterization section.

Predicting ascospore showers. Ascospores are presumed to be discharged in discreet daily events (henceforth referred to as ascospore-discharge events) on or after the onset of pseudothecia maturity, when daily rainfall meets or exceeds a threshold value
(RAD_threshold). During an ascospore-discharge event on day $t$, the total number of ascospores discharged $\left(A D_{t}\right)$ is calculated as the product of the total number of ascospores available for discharge on that day $\left(A T_{t}\right)$ and the fraction of $A T_{t}$ discharged during an ascospore-discharge event ( $A D \_$fraction) (equation 1). AD_fraction is presumed to be constant and is a parameter of the model. $A T$ is updated on the following day $\left(A T_{t+1}\right)$ and is the sum of nondischarged ascospores after day $t$ and the number of ascospores that matured on day $t\left(A N_{t}\right)$ (equation 2). $A N_{t}$ is calculated as the difference of the cumulative number of mature ascospores (CNMS) between days $t$ and $t+1$.

$$
\begin{gathered}
A D_{t}= \begin{cases}0 & \text { if rain }<R A D_{-} \text {threshold } \\
A T_{t} \times A D_{-} \text {fraction } & \text { if rain } \geq R A D_{-} \text {threshold }\end{cases} \\
A T_{t+1}= \begin{cases}A T_{t}+A N_{t} & \text { if rain }<R A D_{-} \text {threshold } \\
A T_{t} \times\left(1-A D_{-} \text {fraction }\right)+A N_{t} & \text { if rain } \geq R A D_{-} \text {threshold }\end{cases}
\end{gathered}
$$

As already mentioned, pseudothecia on infected stubble release a succession of ascospores, over a period of several months, often about 4 months $(10,22)$. This mechanism has been captured in the model using the cumulative Beta distribution function to describe the relationship between CNMS and total FPM days. The Beta distribution was chosen because it can produce a wide variety of suitable shapes and because it is confined to lie between values of 0 and 1 (23). In Vose (23), the probability density function of a Beta distribution is defined as

$$
f(x)=\frac{x^{\alpha-1}(1-x)^{\beta-1}}{\int_{0}^{1} t^{\alpha-1}(1-t)^{\beta-1} d t}
$$

The Beta distribution has two parameters, $\alpha$ and $\beta$. The function can be scaled to any range by the addition of two further parameters, the start value and end value of the range, in our case these are the beginning and end points of the process of maturation of ascospores, PM_begin and PM_end, respectively. The function that describes CNMS can easily be implemented in Excel using the BETADIST function.

Model parameterization. A list of the parameters and their values is shown in Table 1. A parsimonious and conditional approach was taken to fitting the parameters that affect the prediction of onset of pseudothecia maturity. The values of 10 days for $T \_t h r e s h o l d \_d u r a t i o n$ and 7 days for $R \_t h r e s h o l d \_d u r a t i o n$ were chosen arbitrarily and fixed to avoid overparameterization of the model. The main effect of the 10-day value of T_threshold_duration is to smooth the temperature data and thereby reduce the number of changes between the FPM and non-FPM states of the model. The value of 7 days for $R \_$threshold_duration recognizes that rainfall has a somewhat persistent effect on the water content of crop residue. In reality, the nature of this relationship is dependent on a large number of factors, and a detailed representation is beyond the scope of this work.

The values of the remaining three parameters that describe the onset of pseudothecia maturity, $T \_$threshold, $R \_$threshold, and $P M \_$begin, were estimated in three steps. Firstly, initial estimates were generated through literature review. It has been reported that mean daily temperatures of $14^{\circ} \mathrm{C}(12,13)$ or between 9 and $16^{\circ} \mathrm{C}$ (16) were most favorable for pseudothecia maturation. However, pseudothecia and mature asci of blackleg fungus can be produced in culture media at temperatures of 16 to $25^{\circ} \mathrm{C}$ (28). In controlled environment, when tested in the range from 7 to $20^{\circ} \mathrm{C}$, the pseudothecia maturation process continued to occur at the highest temperature (13). Regarding moisture requirement, Pérès et al. (13) reported that pseudothecia maturation took place at $14^{\circ} \mathrm{C}$ with $2.5 \mathrm{~mm}$ of simulated rain in every $3-, 4-$, or 8 -day interval, and less frequent rain resulted in increased time to the start of maturity. Bernard et al. (1) indicated that pseudothecia maturation could take place with a relative humidity over $90 \%$. Furthermore, a 
number of studies show that excessive wetness is not a prerequisite for progression of pseudothecia maturity $(14,16)$. In relation to the required time of onset of pseudothecia maturity, it has been reported that the first release of ascospores occurs in France after 16 to 19 rainy days following harvest, when the average temperature falls to around $14^{\circ} \mathrm{C}(12)$.

Secondly, we determined the optimal value of $P M \_$begin for a range of combinations of $T \_$threshold and $R \_$threshold to fit field observations of pseudothecia maturity collected in 1998 at Mount Barker in Western Australia. T_threshold ranged from 14 to $26^{\circ} \mathrm{C}$ in steps of $1^{\circ} \mathrm{C}$, and $R \_$threshold was 2 , 4 , or $6 \mathrm{~mm}$. These ranges encompassed the levels reported in the literature as described previously.

Over this range of $T \_$threshold and $R \_$threshold, values of $P M \_$begin can be found to match the observed value within 1 day for the 1 year calibration data set. This process produces a range of values of PM_begin as low as 14 days and as high as 58 days (Fig. 1). The estimate for conditions in France of 16 to 19 rainy days with a temperature around $14^{\circ} \mathrm{C}$ before ascospore maturity, reported previously (12), is consistent with this relationship.

Thirdly, the same set of values of $T$ _threshold and $R \_$threshold were combined with values of $P M \_$begin ranging from 13 to 53 days and compared with observed time to ascospore maturity for 3 years (1998 to 2000) at Mount Barker. Differences in the fit were observed for the tested combinations (Fig. 2). The set of values that produced the smallest root mean squared deviations between observation and prediction for the 189 tested combinations of the three parameters were $22^{\circ} \mathrm{C}, 4 \mathrm{~mm}$, and 43 days for $T \_$threshold, $R \_$threshold, and PM_begin, respectively.

The parameters that influence discharge of ascospores were set either from the literature or by calibration using a set of field observations of daily ascospore discharge measured using a spore trap in 1999 at Mount Barker, Western Australia. RAD_threshold was chosen based on the literature $(4,10,11)$, which indicates that small amounts of rainfall and/or heavy dews and high humidity can trigger ascospore release. For this reason, we chose a value of $0.20 \mathrm{~mm}$ of daily rainfall for $R A D \_$threshold, which is the minimum measurable daily rainfall in our meteorological data sets.

The value for PM_end was based on the 1999 Mount Barker data set. During the observation period (5 May to 31 October), the spore trap recorded discharge of ascospores on 113 days. The spore trap was out of order for 12 days during periods when spores were being discharged on most days so we chose a value of 125 days (113 measured days +12 days out of order) for PM_end. We did not have any prior basis for estimating the parameter $A D \_$fraction, but a value of 0.40 worked well for fitting the model to the calibration data.

To ascertain $\alpha$ and $\beta$ parameters of the Beta distribution (equation 3), we used a reparameterized version of the Beta function as described by Vose (23) (equations 4, 5, and 6). These equations require estimation of two alternate parameters, $P M_{-}$peak and $P M_{-}$peaksharpness, which we find more biologically intuitive than the unmodified parameters. These equations also calculate the mean of the distribution $(\mu) . P M_{-}$peak is the mode of the distribution. It dictates the time lag following $P M \_$begin before the peak rate of ascospore maturity occurs. PM_peaksharpness determines the width of the peak generated by the Beta function and like $P M_{-}$peak can be estimated by comparison with measured distributions. Literature shows that the peak of ascospore showers (PM_peak) usually occurs 1 or 2 months after the onset of pseudothecia maturity $(7,10,22)$. Our calibrated value for this parameter was 30 days. A value of 2 for PM_peaksharpness was chosen by calibration.

$\alpha=\frac{\left(\mu-P M_{\_} \text {begin }\right)\left[2\left(P M_{-} \text {begin }+P M_{-} \text {peak }\right)-P P_{-} \text {begin }-\left(P M_{-} \text {begin }+P M_{-} \text {end }\right)\right]}{\left[\left(P M \_ \text {begin }+P M \_ \text {peak }\right)-\mu\right]\left[\left(P M \_ \text {begin }+P M \_ \text {end }\right)-P M \_ \text {begin }\right]}$

$$
\beta=\frac{\alpha\left[\left(P M_{-} \text {begin }+P M_{-} \text {end }\right)-\mu\right]}{\left(\mu-P M_{-} \text {begin }\right)}
$$

$$
\mu=\frac{P M_{-} \text {begin }+\left(P M_{-} \text {peaksharpness } \times P M_{-} \text {peak }\right)+P M_{-} \text {end }}{P M_{-} \text {peaksharpness }+2}
$$

Model testing. Prediction of onset of pseudothecia maturity was tested with observed data collected for 3 years, 1998 to 2000 ,

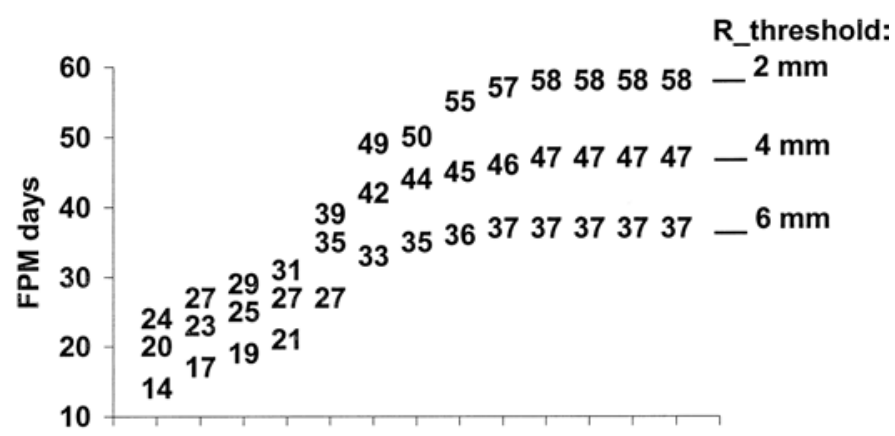

131415161718192021222324252627

\section{T_threshold $\left({ }^{\circ} \mathrm{C}\right)$}

Fig. 1. Calibration of temperature (T_threshold) and rainfall (R_threshold) thresholds to parameterize the optimum favorable for pseudothecia maturity (FPM) days required for the onset of pseudothecia maturity (PM_begin) of blackleg, Leptosphaeria maculans. The predicted onset of maturity date matched within 1 day of observation for the FPM days shown in the figure for each combination of $T \_$threshold and $R_{-}$threshold. The 1999 observed data from Mount Barker, Western Australia, were used for this calibration.

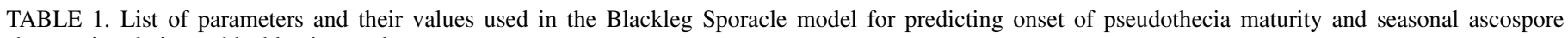

\begin{tabular}{|c|c|c|c|}
\hline Parameter & Definition & Unit & Value \\
\hline$A D_{-}$fraction & Fraction of mature ascospores released during an ascospore discharge event & Unitless & 0.40 \\
\hline PM_begin & Number of days favorable for pseudothecia maturation before the onset of pseudothecia maturity & Days & 43 \\
\hline PM_end & $\begin{array}{l}\text { Number of days favorable for pseudothecia maturation from } P M \_ \text {begin until pseudothecia } \\
\text { maturation ends }\end{array}$ & Days & 125 \\
\hline$P M_{-}$peak & $\begin{array}{l}\text { Number of days favorable for pseudothecia maturation from } P M \_ \text {begin until the rate of } \\
\text { pseudothecia maturation reaches a maximum }\end{array}$ & Days & 30 \\
\hline PM_peaksharpness & Dimensionless number that affects the shape of the pseudothecia maturation function & Unitless & 2 \\
\hline R_threshold & $\begin{array}{l}\text { Lower limit of total accumulated rain required for conditions to be favorable for pseudothecia } \\
\text { maturation }\end{array}$ & $\mathrm{mm}$ & 4 \\
\hline R_threshold_duration & Time period used in calculating the value of $R \_$threshold & Days & 7 \\
\hline RAD_threshold & Amount of daily rainfall on and above which an ascospore discharge event can take place & $\mathrm{mm}$ & 0.20 \\
\hline T_threshold & $\begin{array}{l}\text { Upper limit of the mean daily temperature required for conditions to be favorable for pseudothecia } \\
\text { maturation }\end{array}$ & ${ }^{\circ} \mathrm{C}$ & 22 \\
\hline T_threshold_duration & Time period used in calculating the value of $T \_$threshold & Days & 10 \\
\hline
\end{tabular}
showers in relation to blackleg in canola 
in four locations, ranging from north to south, in the grain belt of Western Australia. The locations were East Chapman $\left(28.30^{\circ} \mathrm{S}\right.$ and $\left.115.05^{\circ} \mathrm{E}\right)$, Wongan Hills $\left(30.51^{\circ} \mathrm{S}\right.$ and $\left.116.44^{\circ} \mathrm{E}\right)$, Merredin $\left(31.31^{\circ} \mathrm{S}\right.$ and $\left.118.10^{\circ} \mathrm{E}\right)$, and Mount Barker $\left(34.38^{\circ} \mathrm{S}\right.$ and $117.32^{\circ} \mathrm{E}$ ) (Fig. 3). Western Australia characteristically has a Mediterranean climate: the summer (December through February) is hot and dry, temperatures start declining with the arrival of rain in autumn (March through May), winter (June through August) is cool and rainy, and temperatures start rising with decreasing rain in the spring (September through November). The summer temperatures tend to decrease as the latitude increases from north to south (Fig. 3). Predicted ascospore showers were compared with spore trap data collected during the 1999 and 2000 seasons at Mount Barker and the 2000 season at East Chapman.

Observation of onset of pseudothecia maturity. Blackleginfected canola stems from the previous year's crop were collected each week after the first of January each year. In 1998, 20 canola stems were collected each week from one commercial field in each region. In 1999 and 2000, 10 canola stems were collected each week from each of two commercial fields near Wongan Hills and each of four commercial fields at the other locations. Each stem was observed microscopically for maturation of blackleg pseudothecia. Details of the method are given by Khangura et al. $(7,8)$.

Observation of discharge of ascospores. Discharge of blackleg ascospores was measured from 5 May to 31 October 1999 and 13 March to 31 October 2000 at Mount Barker and from 28 March to 31 October 2000 at East Chapman. A 7-day recording volumetric spore trap (Burkard Scientific, Rickmansworth, Hertfordshire, England) was set up in a field in which canola had been infected with blackleg grown in the previous season. The spore trap was out of order for four periods in 1999 (22 to 27 May, 5 to 7 June, 12 to 14 June, and 25 to 28 September), once in 2000 (26 April to 8 May) at Mount Barker, and once in 2000 (20 to 27 June) at East Chapman. The spore trap sampled air at approximately 10 liters/min. Ascospores were counted for every second hour of the day, and daily counts were calculated from the hourly counts. Details of this method are given by Khangura et al. $(7,8)$.

Weather data. For Wongan Hills and Merredin, the weather records of daily mean temperature (degrees Celsius) and daily total rainfall (millimeters) were accessed through automatic weather stations run by the Western Australian Department of Agriculture. For Mount Barker, weather data recorded by the Australian Bureau of Meteorology were used. For East Chapman, measured data were not available. Therefore, an interpolated data set supplied by

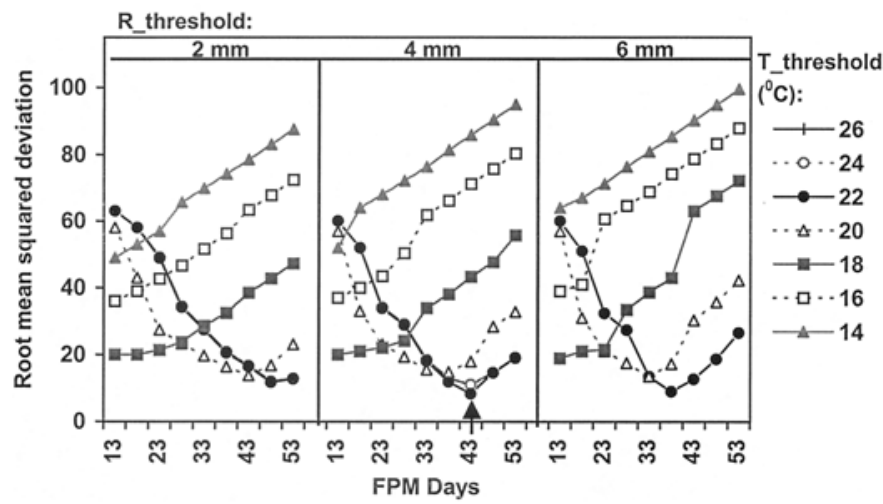

Fig. 2. Calibration of seven temperatures ( $T$ _threshold) and three rainfall ( $R$ _threshold) thresholds under nine tested values $(13,18,23,28,33,38,43$, 48 , and 53 days) of favorable for pseudothecia maturity (FPM) days required for onset of pseudothecia maturity of blackleg, Leptosphaeria maculans. The numbers show the root mean squared deviation (RMSD) of predicted onset of pseudothecia maturity based on observations during 1998, 1999, and 2000 at Mount Barker, Western Australia. Arrow indicates the RMSD for model parameter set. the Queensland Department of Natural Resources and Mines was used (the procedure has been described by Jeffrey et al. [6]).

Operation of the model. Harvest of canola in Western Australia occurs during November and December depending on location, earlier in the north and center, and later in the south. All model runs were started on 1 January, which is after harvest in all areas and before it becomes likely that average temperatures will fall below $22^{\circ} \mathrm{C}$.

To predict the timing of onset of pseudothecia maturity, the model was run with 1998, 1999 and 2000 weather data for all four locations. Pseudothecia maturity was expressed as the day of the year (DOY).

To predict ascospore showers, the model was run, using the parameters specified in the model parameterization section, with 1999 and 2000 weather data for Mount Barker and 2000 weather data for East Chapman. The output of the model was the fraction of the seasonal total of ascospores released on each day. The observed data was converted to fraction of observed total ascospores measured during the season $(42,145,20,878$, and 2,735 for 1999 and 2000 seasons at Mount Barker and 2000 season at East Chapman, respectively). For the purpose of comparison, zero values were substituted for simulated values for the days when the spore trap was not functioning. All data were summarized as daily or weekly totals.

Statistical analysis. Performance of the model was analyzed statistically using both a correlation-regression approach (prediction versus observation) and a deviation approach (prediction minus observation). The regression-based statistics that were employed are the coefficient of determination $\left(R^{2}\right)$ for the $1: 1$ or $y=x$ line and the slope $(m)$ of the regression line, which was forced through the origin. The standard error of the slope, the level of significance $(P)$ to test whether the slope is different to 1 , and the number of points $(n)$ employed in the regression analysis are mentioned. Time series data for ascospore showers were log-transformed and a common value of 1 was assigned for all of the zero values.

The deviation-based statistics employed are mean squared deviation (MSD) and its three components-squared bias (SB), squared difference between predicted and observed standard deviations (SDSD), and lack of positive correlation weighted by the standard deviations of prediction and observation (LCS). MSD measures the total deviation between predictions and observations. The lower the value of MSD, the closer the prediction is to the observation. SB indicates the mean agreement between the model and observation, whereas SDSD and LCS together show how closely the model predicts variability around the mean. There are two sources of this variability, magnitude of fluctuation among the $n$ observation and pattern of the fluctuation across $n$ observation, SDSD and LCS quantify the model's ability to describe the former and latter variability, respectively.

More details on the deviation statistics and the equations used for calculating the statistics are provided in Kobayashi and Salam (9).

Sensitivity analysis of the parameters in relation to pseudothecia maturity. The three parameters, $T \_$threshold, $R \_$threshold, and $P M \_$begin, that describe the onset of pseudothecia maturity were subjected to sensitivity analysis. This was done to determine the relative importance of these parameters and to ascertain that the parameters that were chosen by calibration with a subset of test data were appropriate for the entire data set. The sensitivity analysis was conducted according to a factorial design (21). Seven levels of $T$ threshold $\left(14,16,18,20,22,24\right.$, and $\left.26^{\circ} \mathrm{C}\right)$, three levels of $R \_$threshold $(2,4$, and $6 \mathrm{~mm}$ ), and seven levels of PM_begin (23, 28, 33, 38, 43, 48, and 53 days) were tested. These parameter values were chosen to bracket the base parameter set $\left(22^{\circ} \mathrm{C} T\right.$ threshold, $4 \mathrm{~mm} R \_$threshold, and 43 days $P M \_$begin $)$. This range of $T$ threshold and $R \_$threshold encompasses laboratory and field observations from around the world $(12,13,16$, 
25,28). The values for $P M \_$begin also reflect those reported in the literature $(5,13,15,19)$.

The model was run with all combinations of parameters (147 parameter sets) for each season in all four locations. The same weather data sets as those used in the model testing were used. Model output of the timing of onset of pseudothecia maturity (DOY) was compared with observation, using root mean squared deviation (RMSD).

\section{RESULTS}

Dynamics of pseudothecia maturity. An example of the progression of pseudothecia maturity as simulated by the model is shown in Figure 4. For the specific example of Wongan Hills in the 2000 season, the maturity process commenced in the middle of January, when both temperature and rainfall became favorable. Toward the end of January, temperature rose above the threshold and rain stopped falling, halting the pseudothecia maturity process. Rainfall in early March was well above the threshold, but the temperature remained above the threshold. The progress of pseudothecia maturity started again with falling temperature and sufficient rains during the third week of March. After that time, temperature for the most part remained favorable but occasional lack of rain temporarily stopped the pseudothecia maturity process. The model predicted the start of maturity on 23 June, when the total of FPM days reached 43. This time was close to the observed

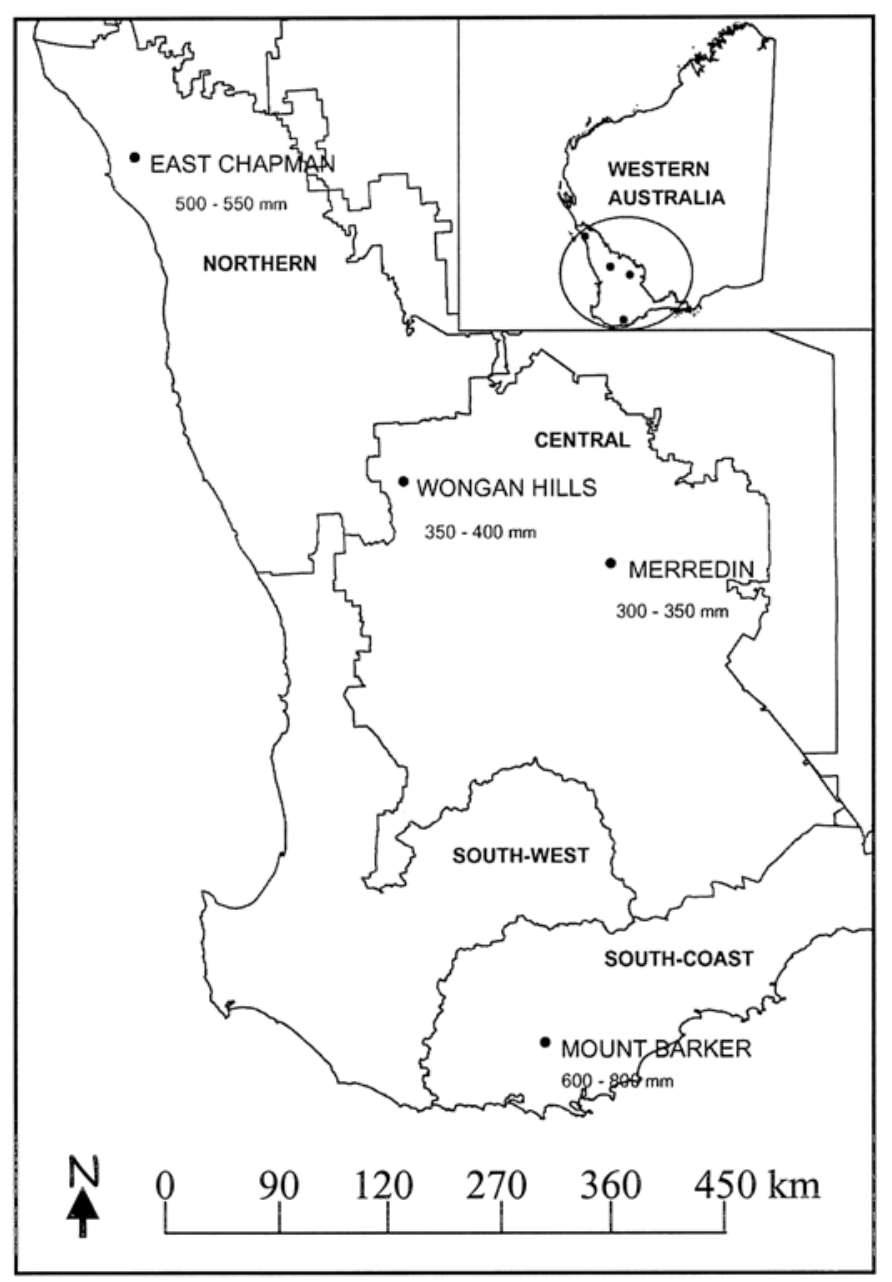

Fig. 3. Top right, map of Western Australia, with the grain belt circled. Bottom left, the grain belt is shown at a larger scale, with black spots indicating the four locations where the Blackleg Sporacle model was calibrated or tested. The numbers below each location show the range of annual rainfall. mean of the onset of pseudothecia maturity in the location, which was 29 June (Fig. 4).

The onset of pseudothecia maturity-Prediction versus observation. The model predicted the observed onset of pseudothecia maturity quite well. Figure 5 shows the predicted versus observed values across the three seasons in the four locations of Western Australia $\left(R^{2}=0.90\right.$, slope $=1.01$, standard error $=0.02$, $P>0.05$ [NS], $n=12$ ). Across the locations and years, the onset of pseudothecia maturity occurred as early as 17 March (DOY 77) and as late as 6 July (DOY 188). The model predicted this diversity with reasonable accuracy. The mean difference between prediction and observation was only 2.08 days. The model also closely predicted the magnitude of fluctuation (standard deviation = 34.21) among the 12 observations (standard deviation $=33.36$ ). The deviation between observed and predicted values of the timing of onset of pseudothecia maturity across the locations and seasons was $6.99 \%$.

There were some underestimations and overestimations in model's predictions at each of the four locations (Fig. 5). Figure 6 shows an analysis of the nature of these variations, using the MSD technique. The MSD varied between 69.17 and 157.02 for the four locations, the smallest being at Mount Barker (the calibration site), closely followed by Merredin, and the largest being at Wongan Hills, closely followed by East Chapman. The nature of this variability was similar at Mount Barker and Merredin, which were characterized by small SB and small SDSD but relatively large LCS. Small SB indicates that the difference between the means (in this case, across the three seasons) of prediction and observation was small. A small SDSD indicates that the model largely simulated the magnitude of fluctuation between the three seasons. The large LCS indicates that the model did not adequately simulate the pattern of the fluctuation across the seasons. At Wongan Hills, the model largely failed to simulate the magnitude of seasonal fluctuations due largely to substantial underprediction in 1999 (Fig. 6, note the relatively large SDSD component). The means (across the three seasons) of prediction and observation did not agree well at East Chapman where all pre-

Total rainfall in the last 7 days
10-day temperature average
Observed time of onset of pseudothecia maturity
Predicted progression towards onset of pseudothecia maturity

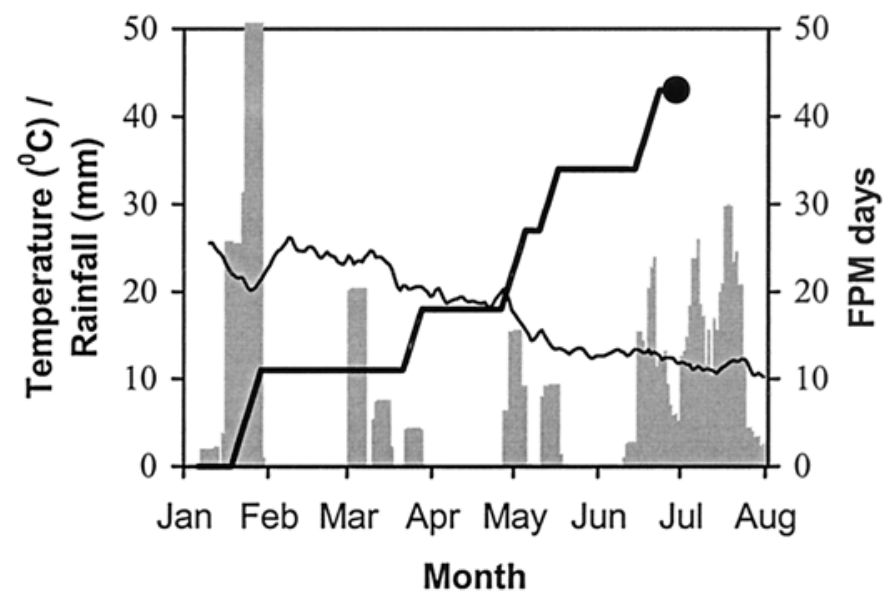

Fig. 4. Step-wise progression toward onset of pseudothecia maturity in relation to daily weather factors, temperature and rainfall. Forty-three accumulated favorable for pseudothecia maturity (FPM) days indicates onset of maturity. A calendar day is a FPM day when the mean daily temperature for the preceding 10-day period (T_threshold_duration) is $<22^{\circ} \mathrm{C}$ ( $T \_$threshold) and the total rainfall for the last 7 days ( $R \_$threshold_duration) is $\geq 4 \mathrm{~mm}$ (R_threshold). This example represents the year 2000 at Wongan Hills, Western Australia. 
dicted values were less than observed (Fig. 6, note the relatively large SB component; Fig. 5).

The ascospore shower-Prediction versus observation. Figure 7 shows simulated and observed daily ascospore showers for 1999 and 2000 at Mount Barker and 2000 at East Chapman (the 1999 data set at Mount Barker was used for calibration). Note that the observed data were not available during the onset of pseudothecia maturity in 1999 at Mount Barker and also that there were some sporadic missing data during May, June, and September. In 2000 at Mount Barker, there were also some missing data during the measurement period. It appears that the model largely captured the pattern of ascospore discharge for the data sets. There were, however, some variations in the magnitude of ascospore showers that the model did not predict. The weekly totals of ascospore showers between observation and prediction were compared in statistical analysis. Quantitatively, about $77 \%$ of the variability was explained at Mount Barker in 1999 when the predicted values

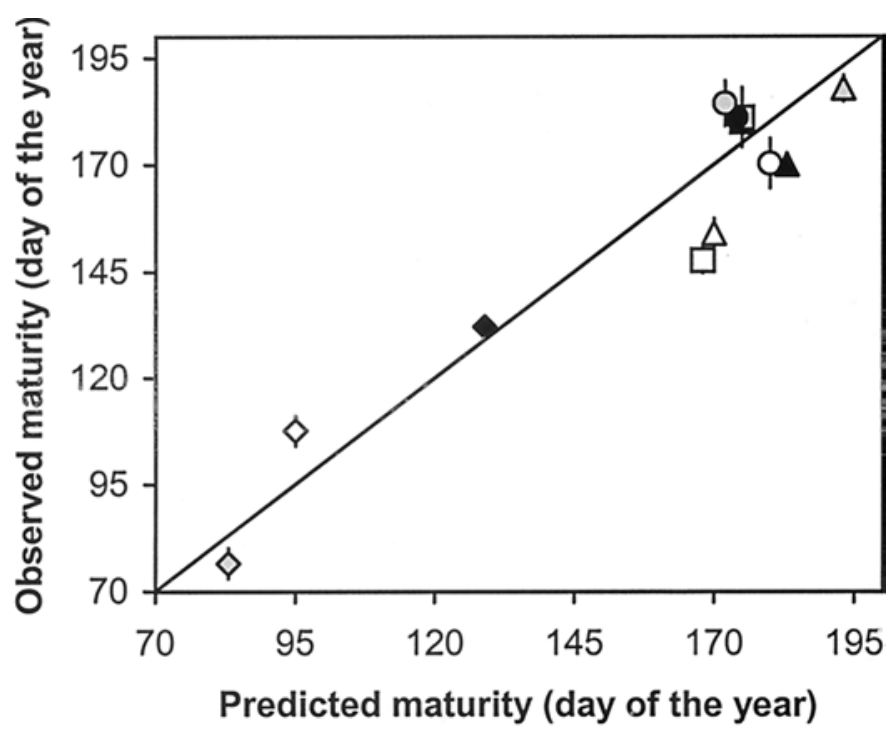

Fig. 5. Comparison between the predicted and observed timing of onset of pseudothecia maturity across four locations of Western Australia during three consecutive seasons. Observed values are represented by diamonds for Mount Barker, squares for Wongan Hills, circles for Merredin, and triangles for East Chapman. The 1998 season is designated by a closed black symbol; the 1999 by an open symbol; and the 2000 season by a closed gray symbol. The Mount Barker data sets were used for model calibration.

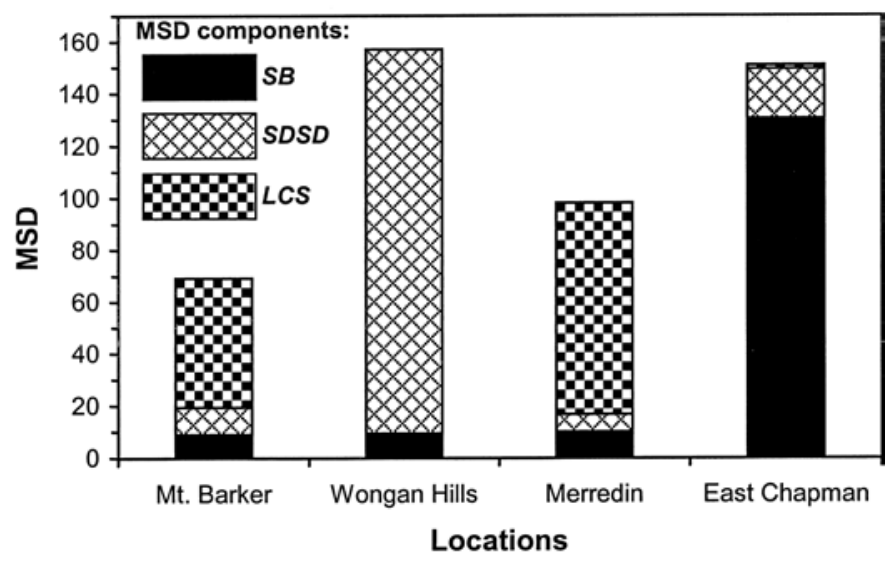

Fig. 6. Mean squared deviation (MSD) and its components, squared bias (SB), squared difference between standard deviations (SDSD), and lack of correlation weighted by the standard deviations (LCS), comparing predicted and observed onset of pseudothecia maturity of blackleg, Leptosphaeria maculans, on infected canola stubble in four locations in Western Australia across three seasons. The Mount Barker data sets were used for model calibration. were regressed over the observed ones $\left(R^{2}=0.77\right.$, slope $=1.00$, standard error $=0.09, P>0.05[\mathrm{NS}], n=24)$. During the 2000 season at Mount Barker, the pattern of variability was mostly captured by the model as indicated by the regression between the predicted and observed values $\left(R^{2}=0.66\right.$, slope $=0.98$, standard error $=0.09, P>0.05[\mathrm{NS}], n=31)$. At East Chapman $(2000$ season), the linear regression explained $93 \%$ of the variability $\left(R^{2}=\right.$ 0.93 , slope $=1.05$, standard error $=0.05, P>0.05[\mathrm{NS}], n=29$ ).

Parameter sensitivity for pseudothecia maturity. The three parameters that explained the timing of onset of pseudothecia maturity were used for sensitivity analysis considering values both below and above the standard parameter set. Results have been expressed in terms of RMSD from observation. Figure 8A shows the aggregate RMSD across all locations for all combinations of the seven tested values of $P M \_$begin, seven values of $T \_$threshold, and three values of $R \_$threshold. It is apparent that accuracy of the model is more sensitive to $T$ threshold than to $R \_$threshold. In general, increasing or decreasing the value of $T \_$threshold from $22^{\circ} \mathrm{C}$ (as used in the model) caused increased deviation from observation; however, there was not much difference between 22 and $20^{\circ} \mathrm{C}$. The RMSD was similar for all three values of

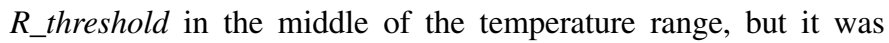
marginally lower for $4 \mathrm{~mm}$. Figure 8 shows a weak interaction between $T \_$threshold and $R \_$threshold.

The standard parameter set $\left(22^{\circ} \mathrm{C}\right.$ for $T$ threshold, $4 \mathrm{~mm}$ for $R \_$threshold, and 43 FPM days for PM_begin) produced an RMSD of 11 for the aggregate of all locations (Fig. 8A). The parameter set that produced the closest agreement with observation for the aggregate of all locations (RMSD 9) was $22^{\circ} \mathrm{C}$ for $T \_$threshold, $6 \mathrm{~mm}$ for $R \_$threshold, and 28 FPM days for $P M \_$begin. The same parameter set also produced the best agreement with observation at Wongan Hills and East Chapman (Fig. 8B and D). On the other hand, the best agreement at Merredin resulted from the parameter set of $16^{\circ} \mathrm{C}$ for $T \_$threshold, $2 \mathrm{~mm}$ for $R \_$threshold, and 28 FPM days for PM_begin (Fig. 8C). Results revealed that a number of parameter sets were able to reduce the overall deviation for particular locations relative to the standard set. In doing so, they tended to increase deviation at other loca-

\section{Observation}
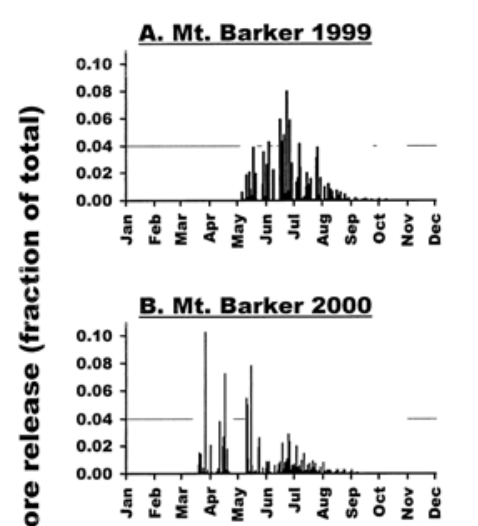

\section{East Chapman 2000}

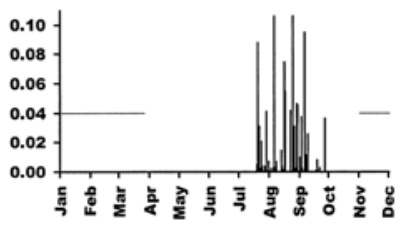

Prediction
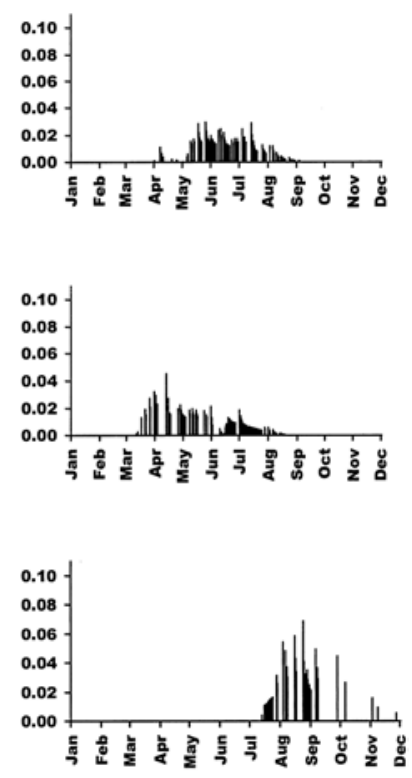

Fig. 7. Daily ascospore showers, observation and prediction, from blackleg (Leptosphaeria maculans)-infected canola stubble in 1999 and 2000 at Mount Barker, and in 2000 at East Chapman, Western Australia. The 1999 data set at Mount Barker was used for model calibration. Lines across the $x$ axis indicate the time period when observed data were not available. 
tions (especially Mount Barker [Fig. 2]). In summary, none of these sets were demonstrably superior to the standard set in predicting the onset of pseudothecia maturity in all four locations of Western Australia.

\section{DISCUSSION}

The onset of pseudothecia maturity. The mean of the observed times of onset of pseudothecia maturity across the three seasons for the four locations varied widely: 15 April (105 DOY) at Mount Barker, 19 June (170 DOY) at Wongan Hills, 28 June (179 DOY) at Merredin, and 20 June (171 DOY) at East Chapman. The model, in general, distinguished these differences. Except for East Chapman, the predicted mean timing was within 4 days of observation. At East Chapman, the model overestimated the mean timing of pseudothecia maturity by 11 days. One possible explanation for this overestimation at East Chapman is that the weather data that we used to run the model may not have adequately represented this location. Because measured weather data were not available for East Chapman, we used data that were interpolated from the nearest weather stations.

The model captured the pattern of season-to-season variability in the timing of onset of pseudothecia maturity well in all but one region. At Merredin, the model did not predict the pattern or order (year-to-year) of observed pattern of pseudothecia maturity. At that location, however, observed seasonal variability of the timing of onset of pseudothecia maturity was very small (standard deviation $=6$ days) compared with the other three regions (standard deviations ranged between 14 and 23 days), and the predicted seasonal variability was even smaller (standard deviation $=3$ days).

The ascospore showers. Overall, the model satisfactorily simulated the pattern of ascospore showers averaged for weekly periods; however, agreement with daily observations was not as good. This lack of agreement was probably due to the simplicity of the model in relation to triggering and magnitude of ascospore showers. Ascospore showers were triggered daily in the model by rainfall. It is widely known that rainfall is a major factor triggering ascospore release (4); however, there are a number of reports indicating that ascospore discharge can occur with heavy dews and/or high humidity (9). The observed data supports the hypothesis that ascospores were trapped on some days when no rain fell. Another factor may also have contributed to underestimating the magnitude of ascospore release in some periods. A number of studies show that ascospore shower events may take place on an hourly or smaller time scale (10), resulting in more than one ascospore shower in a day if wet conditions prevail. Averaging over weekly periods largely masks the inaccuracies apparent at shorter time intervals probably because triggering events occur frequently over winter in any case.

Parameter sensitivity in relation to pseudothecia maturity. To obtain insight into the relative importance of the model parameters, an analysis was performed of the sensitivity of the model's predictions to variations in parameter values. Errors in estimation of the more sensitive parameters and errors in the associated parts of the model structure may well explain much of the models remaining inaccuracy. For this reason, research relating to these parameters and processes is likely to improve our ability to forecast the timing of ascospore release. Temperature threshold ( $T$ _threshold) was the most sensitive parameter, with substantial degradation of model performance occurring when the value deviated more than $10 \%$ from $22^{\circ} \mathrm{C}$. Changes in the order of $50 \%$ from $4 \mathrm{~mm}$ in the rainfall threshold (R_threshold) did not substantially impair model accuracy.

There was a strong interaction between the threshold parameters and number of FPM days before onset of pseudothecia maturity (PM_begin). As the conditions dictating favorable status became more restrictive, a smaller number of days that met the more stringent requirements were required before maturity was ob- served. This trade-off was particularly apparent at the sites other than Mount Barker. At these sites, a wide range of parameter combinations provided similar results. Summer temperatures are cooler and more variable at Mount Barker, and summer rain is more frequent due to higher latitude and greater coastal influence relative to the other sites. These factors combine to produce conditions
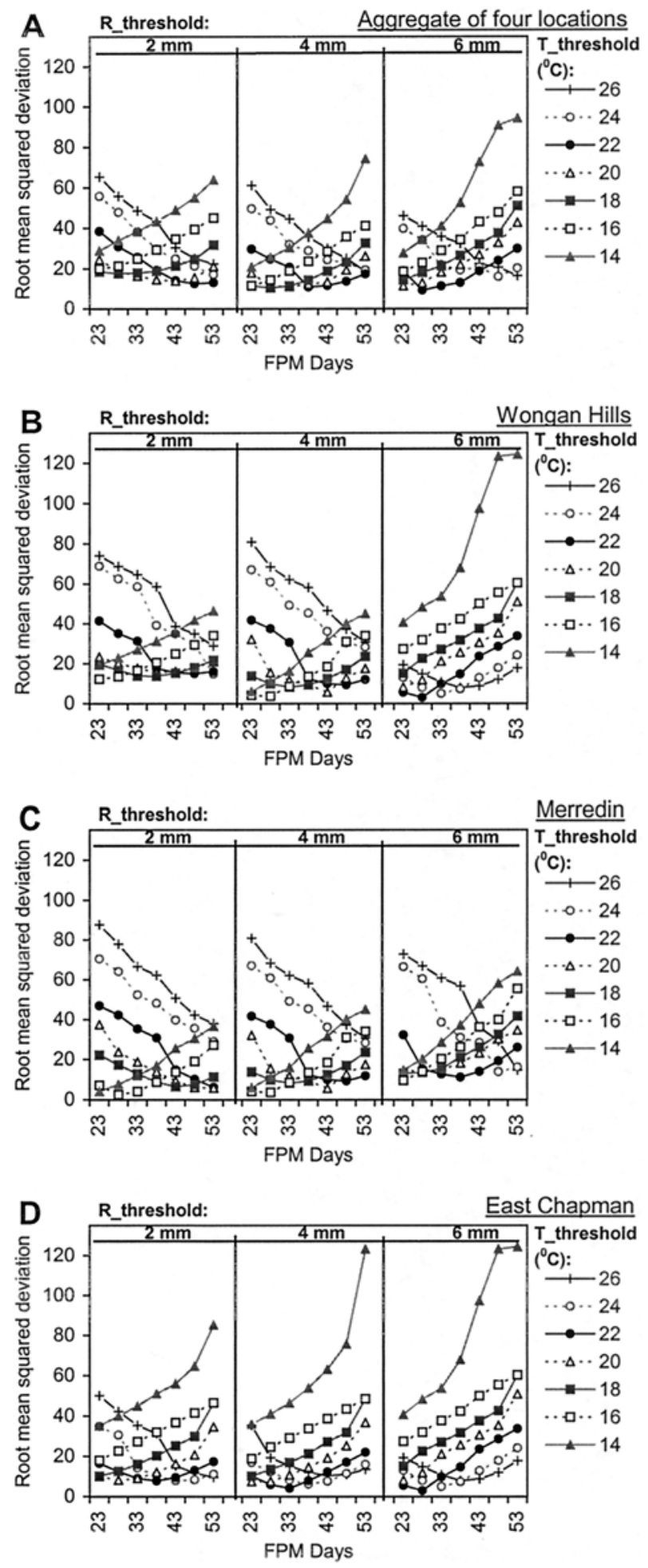

Fig. 8. Sensitivity of seven temperatures ( $T_{-}$threshold) and three rainfall ( $R \_$threshold) thresholds under seven tested values $(23,28,33,38,43,48$, and 53 days) of favorable for pseudothecia maturity (FPM) days required for onset of pseudothecia maturity of blackleg, Leptosphaeria maculans. The numbers show the root mean squared deviation (RMSD) of predicted onset of pseudothecia maturity based on observations: A, aggregate of location RMSDs; B, Wongan Hills; C, Merredin; and D, East Chapman. 
that are variable and often near to the threshold conditions, and they result in a much more variable time of onset of maturity. Consequently, accuracy of the model at Mount Barker is more sensitive to the parameter values, so it follows that data from Mount Barker is the best suited for calibration of the model.

The chosen value of $4 \mathrm{~mm}$ of rainfall in the preceding week as a condition necessary for occurrence of FPM days implies that conditions do not have to be very wet to be suitable for the maturation process. This result is consistent with a number of studies showing that excessive wetness is not necessarily a prerequisite for progression of pseudothecia maturity $(14,16)$.

With respect to temperature, it has been observed that pseudothecia and mature asci of blackleg fungus can be produced in culture medium at temperatures of 16 to $25^{\circ} \mathrm{C}(28)$, or in controlled environment at $20^{\circ} \mathrm{C}$ (13). These results are consistent with the value of $22^{\circ} \mathrm{C}$ used here as an upper limit for suitability. In western Canada, it has been observed that extremely low temperatures stop the pseudothecia maturation process (15). However, in Western Australia temperature is never far below optimum between harvest and onset of maturity. For this reason, a low temperature threshold is not required in Western Australia but may be necessary in many other canola growing regions.

The prediction of ascospores production by L. maculans is very important for forecasting and disease management in canola and oilseed rape. There has been a lot of research on development of epidemics of this disease, whereas little has been done to predict its onset through prediction of ascospore release from infected crop residues. This study is an attempt to fill this gap. In this paper, we have managed to mimic the major environmental effects that drive maturation of pseudothecia. The resulting model is a useful tool to enhance understanding of regional and seasonal variability of pseudothecia maturation and ascospore discharge.

The model is useful in its current form to assist with decisions relating to time of planting of canola in Western Australian conditions. In some years where relatively hot and dry conditions have prevailed prior to the first rains of autumn, the model can confidently predict that canola sown at the first opportunity will have passed its stage of seedling susceptibility before pseudothecia will mature on nearby canola residues. In other years, it is apparent at the time of the first sowing opportunity that early planting will not allow the crop to avoid exposure to ascospores during the susceptible period and that other management practices must consequently be employed to reduce risk of loss.

The model's predictions were not highly accurate in all cases, with differences of up to 2 weeks occurring between the predicted and observed time of onset of maturity. In addition, there are several factors that influence the effect that blackleg disease will have on crop yield that the model does not account for. In particular, the model does not predict the absolute numbers of ascospores that will be released from crop residue, only the timing of release. For these reasons, the model is probably not useful as a guide to tactical management of blackleg in crops.

Future research aimed at refining our understanding of the effects of temperature on maturation of ascospores would likely substantially improve our ability to forecast time of maturation. Also, research aimed at quantifying the factors that affect absolute numbers of ascospores produced on crop residues would be useful in improving management of blackleg.

\section{ACKNOWLEDGMENTS}

The Australian Grains Research and Development Corporation supported this research. We thank several staff of the Department of Agriculture-Western Australia for help, especially J. W. Bowden for critically reviewing the manuscript and M. F. D'Antuono for statistical analyses, and two anonymous reviewers for excellent comments and constructive criticisms.

\section{LITERATURE CITED}

1. Bernard, C., Maisonneuve, C., Poisson, B., Pérès, A., Penaud, A., Pilorgé, E., and van de Putte, B. 2000. Leptosphaeria maculans (Phoma lingam): First results of development of a forecasting climatological system. Proc. 10th Int. Rapeseed Congress, 1999. Online publication sponsored by The Regional Institute Ltd., NSW, Australia.

2. Bokor, A., Barbetti, M. J., Brown, A. G. P., MacNish, G. C., and Wood, P. McR. 1975. Blackleg of rapeseed. J. Agric. Western Aust. 16:7-10.

3. Gladders, P., and Symonds, B. V. 1995. Occurrence of canker (Leptosphaeria maculans) in winter oilseed rape in eastern England 1977-93. Int. Org. Biol. Control Bull. 18:1-11.

4. Hall, R. 1992. Epidemiology of blackleg of oilseed rape. Can. J. Plant Pathol. 14:46-55.

5. Hershman, D. E., and Perkins, D. M. 1995. Etiology of canola blackleg in Kentucky and seasonal discharge patterns of Leptosphaeria maculans ascospores from infested canola stubble. Plant Dis. 79:12251229.

6. Jeffrey S. J., Carter, J. O., Moodie, K. M., and Beswick, A. R. 2001. Using spatial interpolation to construct a comprehensive archive of Australian climate data. Environ. Model. Software 16:309-330.

7. Khangura, R. K., Barbetti, M. J., Salam, M. U., and Diggle, A. J. 2001. Maturation of pseudothecia and ascospore discharge by blackleg fungus on canola residues in Western Australia: Preliminary results from field observations. Pages 87-91 in: Proc. 12th Australian Research Assembly on Brassicas. Geelong, Victoria.

8. Khangura, R. K., Barbetti, M. J., Salam, M. U., and Diggle, A. J. 2002. Environmental influences on production and release of ascospores of blackleg and their implications in blackleg management in canola. Pages 50-54 in: Oilseed Updates 2002. Agribusiness Crop Updates 2002, Department of Agriculture, Western Australia, South Perth.

9. Kobayashi, K., and Salam, M. U. 2000. Comparing simulated and measured values using mean squared deviation and its components. Agron. J. 92:345-352.

10. McGee, D. C. 1977. Blackleg (Leptosphaeria maculans (Desm.) Ces. et de Not.) of rapeseed in Victoria: Sources of infection and relationships between inoculum, environmental factors and disease severity. Aust. J. Agric. Res. 28:53-62.

11. McGee, D. C., and Petrie, G. A. 1979. Seasonal patterns of ascospore discharge by Leptosphaeria maculans in relation to blackleg of oilseed rape. Phytopathology 69:586-589.

12. Pérès, A., and Poisson, B. 1977. Phoma du colza: Avancées en épidémiologie. CETIOM-Oléoscope 40:37-40 (in French).

13. Pérès, A., Poisson, B., Le Sourne, V., and Maisonneuve, C. 1999. Leptosphaeria maculans: Effect of temperature, rainfall and humidity on the formation of pseudothecia. Proc. 10th Int. Rapeseed Congress, 1999. Online publication sponsored by The Regional Institute Ltd., NSW, Australia.

14. Pérès, A., Poisson, B., Penaud, A., Jain, L., and Pilorgé, E. 1999. Leptosphaeria maculans (Phoma lingam): A summary of three years of epidemiological studies (1995, 1996 and 1997). Proc. 10th Int. Rapeseed Congress, 1999. Online publication sponsored by The Regional Institute Ltd., NSW, Australia.

15. Petrie, G. A. 1986. Consequences of survival of Leptosphaeria maculans (blackleg) in canola stubble residue through an entire crop rotation sequence. Can. J. Plant Pathol. 8:353.

16. Petrie, G. A. 1994. Effects of temperature and moisture on the number, size and septation of ascospores produced by Leptosphaeria maculans (blackleg) on rapeseed stubble. Can. Plant Dis. Surv. 74: 141-151.

17. Petrie, G. A. 1995. Patterns of ascospore discharge by Leptosphaeria maculans (blackleg) from 9- to 13-month-old naturally-infected rapeseed/canola stubble from 1977 to 1993 in Saskatchewan. Can. Plant Dis. Surv. 75:35-43.

18. Poisson, B., and Pérès, A. 1999. Studies related to maturation of Leptosphaeria maculans pseudothecia on rapeseed stubbles infected by stem canker. Proc. 10th Int. Rapeseed Congress, 1999. Online publication sponsored by The Regional Institute Ltd., NSW, Australia.

19. Rempel, C. B., and Hall, R. 1993. Dynamics of production of ascospores of Leptosphaeria maculans in autumn on stubble of the current year's crop of spring rapeseed. Can. J. Plant Pathol. 15:182-184.

20. Salibuury, P. A., Ballinger, D. J., Wratten, N., Plummer, K. M., and Howlett, B. 1995. Blackleg disease on oilseed Brassica species in Australia: A review. Aust. J. Exp. Agric. 35:665-672.

21. Teng, P. S., Blackie, M. J., and Close, R. C. 1977. A simulation analysis of crop yield loss due to rust disease. Agric. Syst. 2:189-198.

22. Thürwächter, F., Garbe, V., and Hoppe, H.-H. 1999. Ascospore discharge, leaf infestation and variations in pathogenicity as criteria of predict impact of Leptosphaeria maculans on oilseed rape. J. Phytopathol. 147:215-222. 
23. Vose, D. 2000. Risk Analysis: A Quantitative Guide. 2nd ed. John Wiley \& Sons Ltd., Chichester, NY.

24. West, J. S., Biddulph, J. E., Fitt, B. D. L., and Gladders, P. 1999. Epidemiology of Leptosphaeria maculans in relation to forecasting stem canker severity on winter oilseed rape in the UK. Ann. Appl. Biol. 135:535-546.

25. West, J. S., Kharbanda, P. D., Barbetti, M. J., and Fitt, B. D. L. 2001. Epidemiology and management of Leptosphaeria maculans (phoma stem canker) on oilseed rape in Australia, Canada and Europe. Plant Pathol. 50:10-27.
26. West, J. S., Leech, P. K., Fitt, B. D. L., Welham, S. J., Penaud, A., Pérès, A., and Poisson, B. 1999. Optimising the use of fungicides to control stem canker of oilseed rape. Proc. 10th Int. Rapeseed Congress, 1999. Online publication sponsored by The Regional Institute Ltd., NSW, Australia.

27. Williams, P. H. 1992. Biology of Leptosphaeria maculans. Can. J. Plant Pathol. 14:30-35.

28. Xu, X. H., Hill, C. B., and Williams, P. H. 1987. Environmental conditions for the production of pseudothecia of Leptosphaeria maculans. Acta Mycol. Sin. 6:236-241. 